\title{
Iberoamérica en la Enseñanza Española de la Historia*
}

\section{Iberian America in the Spanish teaching of History}

\section{Ibero-América no Ensino Espanhol de História}

\begin{abstract}
Rafael Valls**
Resumen: La presencia de los países iberoamericanos es una cuestión que ha estado permanentemente asegurada en los libros de texto de la educación secundaria española desde la implantación del sistema educativo liberal, a mediados del siglo XIX, hasta la actualidad. Esta atención se ha dado tradicionalmente tanto en los manuales dedicados a la historia de España como en los que se ocupan de la llamada historia universal, así definida a pesar de su marcado carácter eurocéntrico. Esta presencia continuada de países iberoamericanos ha conocido, sin embargo, distintos grados de intensidad según las épocas, en el sentido de que se ha dedicado mayor o menor extensión en las páginas de los manuales a los contenidos históricos relacionados con el conjunto de estos procesos históricos: esta es la cuestión que abordamos detalladamente en nuestra investigación.
\end{abstract}

Palabras clave: Iberoamérica. Enseñanza de la historia. Manuales escolares.

\begin{abstract}
From the nineteenth century to the present day, since the implementation of the liberal educational system, Iberian American countries have been permanently discussed in textbooks of Spanish secondary education. This attention is traditionally given in both manuals dedicated to the history of Spain and in those that approach the so-called universal history, so defined despite its marked Eurocentric form. This continued presence of Iberian American countries have, however, different levels of intensity according to the time of the publication, in the sense of historical contents related to these historical processes having greater or lesser space in the pages of manuals: that is the issue we cover in detail in our investigation.
\end{abstract}

Keywords: Iberian America. History teaching. School manuals.

Resumo: A presença dos países ibero-americanos é uma questão que tem estado permanentemente assegurada nos livros de texto da educação secundária espanhola desde a implantação do sistema educativo liberal, por volta do século XIX, até a

\footnotetext{
* Este artículo forma parte del proyecto de investigación EDU2009-09425: "La construcción de la identidad y el reconocimiento de la alteridad a través de la enseñanza de las ciencias sociales" (Investigador principal: Joaquín Prats) y también del proyecto de investigación IDEHER (Investigadores de Enseñanza de la Historia en Red: HAR2009-07697-E/HIST), cuyo investigador principal es Ramón López Facal.
}

${ }^{* *}$ Universidad de Valencia (España). E-mail: <Rafael.Valls@uv.es> 
atualidade. Esta atenção tem se dado tradicionalmente tanto nos manuais dedicados à história da Espanha como nos que se ocupam da chamada história universal, assim definida apesar de seu marcado caráter eurocêntrico. Esta presença continuada de países ibero-americanos tem conhecido, no entanto, distintos graus de intensidade segundo as épocas, no sentido de haver sido dedicada maior ou menor extensão nas páginas dos manuais aos conteúdos históricos relacionados como conjunto destes processos históricos: esta é a questão que abordamos detalhadamente em nossa investigação.

Palavras-chave: Ibero-América. Ensino de história. Manuais escolares.

\section{Introducción histórica}

La presencia de los países iberoamericanos es una cuestión que ha estado permanentemente asegurada en los libros de texto de la educación secundaria española desde la implantación del sistema educativo liberal, a mediados del siglo XIX, hasta la actualidad. Esta atención se ha dado tradicionalmente tanto en los manuales dedicados a la historia de España como en los que se ocupaban de la llamada historia universal, así definida a pesar de su marcado carácter eurocéntrico.

Esta presencia continuada de países iberoamericanos ha conocido, sin embargo, distintos grados de intensidad según las épocas, en el sentido de que se ha dedicado mayor o menor extensión en las páginas de los manuales a los contenidos históricos relacionados con el conjunto de estos procesos históricos. Los aspectos que van a centrar nuestra atención en el presente estudio son los relacionados con las poblaciones y sociedades indígenas "precolombinas"; el "descubrimiento", la conquista de la América del centro y del sur y la etapa colonial; el proceso independentista y, por último, los tiempos recientes, entendiendo por ello la historia posterior a la II Guerra Mundial, en la que incluiremos también los actuales movimientos migratorios. En este estudio nos centraremos casi exclusivamente en los manuales de historia y de geografía de la Enseñanza Secundaria Obligatoria (en adelante, ESO, que comprende al alumnado entre los 12 y 16 años de edad). En alguna ocasión recurriremos también a los manuales de historia de la Educación Secundaria Superior o Bachillerato (alumnado entre los 17 y los 18 años) siempre que nos permitan perfilar mejor alguna de las cuestiones abordadas. En la selección de los manuales nos hemos decantado por aquellos que son de uso muy mayoritario en las aulas, dado que este criterio es el más aceptado, por su representatividad, en el mundo de la manualística. En algunas ocasiones muy significativas haremos uso también de algunos manuales "alternativos" refiriéndonos con esta expresión a los manuales que se alejan de los cánones habituales y de los currículos oficiales y que intentan una enseñanzaaprendizaje más activo o participativo por parte del alumnado. 
Se puede afirmar, en una síntesis muy rápida, que el relato ofrecido por los manuales de historia desde la segunda mitad del siglo XIX da una visión bastante simplificada de todos estos procesos históricos, compendiados habitualmente en algunos pocos párrafos de los manuales y en los que el periodo postcolonial apenas si está presente ${ }^{1}$.

Los manuales del primer tercio del siglo XX, fruto del renovado interés historiográfico hispanoamericanista que se desarrolló desde finales del siglo XIX, suelen ser ya más explícitos y desarrollan con mayor detalle las características peculiares tanto del proceso de conquista y colonización como del proceso independentista, adentrándose en las causas y en las consecuencias de los mismos tanto para los países iberoamericanos como para España ${ }^{2}$. Esta incrementada atencional mundo iberoamericano se plasmó de forma explícita en el plan de estudios de bachillerato de 1926, en plena dictadura del general Primo de Rivera, con la inclusión, por primera y única vez, de una asignatura denominada "Nociones de geografía e historia de América"3

Los manuales de historia de los primeros años del franquismo (entre 1938 y 1953) supusieron para estos temas un cambio significativo (excepción hecha de lo ya indicado para el plan de estudios de 1926), aunque de corta duración, pues sus orientaciones fueron eliminadas a partir de la segunda fecha indicada. El cambio consistió, respecto de las cuestiones que nos ocupan, en la extensa presencia otorgada a la "historia del imperio español y de la hispanidad", a la que se dedicaron dos cursos completos: aunque sus contenidos se centraron fundamentalmente en las características generales de la presencia española en Europa y en América durante los siglos XVI, XVII y XVIII, con una exclusiva interpretación nacional católica, en todos estos manuales se dedicó también algunos capítulos al conjunto de temas anotados, incluido el proceso de independencia, con una extensión aproximada de unas diez páginas, bastante superior a la otorgada previamente y a la que se hizo habitual en los manuales posteriores, incluidos los actuales ${ }^{4}$. La drástica reducción del tiempo dedicado a la enseñanza de la historia en los posteriores planes de estudio del periodo franquista, hasta 1975, hizo que todos los temas fueran tratados de una

\footnotetext{
${ }^{1}$ Así ocurre, por ejemplo, en el manual de Fernando de Castro (1850).

${ }^{2}$ Puede servir de ejemplo de este periodo, entre otros posibles, el texto del prestigioso historiador y americanista Rafael Altamira (1934).

${ }^{3}$ Ejemplos de manuales de este plan de estudios son los de Pedro Aguado Bleye (1929) y el de Antonio Jaén Morente (1929), que fue el texto seleccionado para ser manual "único" de esta materia. Todos estos manuales abordan la historia americana desde la perspectiva de las historias generales, esto es, desde las sociedades precolombinas hasta la actualidad, incluyendo también la parte norte de tal continente.

${ }^{4}$ Las interpretaciones dadas por los diferentes autores de los manuales de historia de este periodo son muy parecidas. Tal vez uno de los que más destaque por su nacionalcatolicismo sea el manual del jesuita Feliciano Cereceda (1940).
} 
manera muy abreviada y superficial, luido el de la independencia de los países iberoamericanos, al que, como en el siglo XIX, se le volvió a dedicar tan solo unos escasos párrafos.

En los manuales aparecidos en los primeros años de la transición política española, a partir de 1977, y que han perdurado sin grandes cambios hasta mediados de los años noventa en lo referente a los temas que nos ocupan, la presencia de las cuestiones previamente anotadas aumentó y se hizo presente en dos de las tres asignaturas que estudiaron los alumnos de educación secundaria: por una parte, en los manuales dedicados a la historia de España, entonces significativamente denominada Geografía e Historia de España y de los Países Hispánicos $^{5}$ y, por otra, en los manuales de Historia del Mundo Contemporáneo, en los que se abordaba, desde una perspectiva internacional, los siglos XIX y XX. En estos textos escolares se daba, prácticamente por primera vez, un tratamiento más consistente tanto de las sociedades "precolombinas" como de la historia más reciente, al tiempo que el estudio del tema de la independencia de los países iberoamericanos ya solía contar con un guion bastante persistente de contenidos históricos, que abordaban tanto los precedentes del proceso como de sus causas y una periodización relativamente detallada del mismo, tanto desde una perspectiva más política e institucional como más militar, incluyendo los que podemos considerar como los hitos y personajes más destacados de este proceso. Era también habitual que se tratase brevemente la evolución política y los problemas que los países iberoamericanos tuvieron que abordar tras su independencia. El espacio dedicado a cada uno de estos temas oscilaba, por término medio, entre las dos y las cuatro páginas.

\section{Los actuales programas de historia de la educación secundaria}

Los actuales planes de estudio en vigor son los del año $2007^{6}$ y les caracteriza una orientación enciclopedista, es decir una formulación muy detallada de los aspectos que deben de ser tratados en las aulas en cada curso escolar. Esta situación presente es fruto de los cambios programáticos introducidos a partir del año 2001, con los que se intentó poner fin a las propuestas curriculares de principios de los años noventa, caracterizadas por su carácter abierto y flexible, especialmente en lo referido a la enseñanza secundaria obligatoria.

\footnotetext{
${ }^{5}$ En estos manuales de finales de los años 70 del pasado siglo, aparte del tratamiento tradicional de los temas relacionados con las culturas precolombinas, la conquista y colonización americanas y los procesos independentistas, se añadía un capítulo final sobre la Iberoamérica contemporánea: véase, por ejemplo, el manual de la editorial Anaya: Valdeón, Julio et al. (1981).

${ }^{6}$ Boletín Oficial del Estado, 5-1-2007.
} 
En los programas más recientes, los establecidos en 2007 por el Ministerio de Educación, el único tema iberoamericano explicitado como tal en los currículos de la ESO es el de "la colonización de América" (2 $2^{\circ}$ de ESO). Es en las dos asignaturas de historia del bachillerato (la de historia de España, por una parte, y la del Mundo Contemporáneo, por otra), en donde los temas que nos ocupan tienen un desarrollo mucho más amplio. En la asignatura de historia de España se incluyen tres apartados: "expansión ultramarina y creación del imperio colonial", "emancipación de la América española” y "guerra colonial y crisis de 1898", que se complementan con el tema integrado en la asignatura sobre el mundo contemporáneo que lleva por título el de "Iberoamérica en el siglo XX". Los criterios de evaluación que acompañan a estos programas, en el caso de la asignatura de historia de España, nos permiten profundizar bastante más en las pretensiones del legislador respecto de estos temas. Así se indica que hay que "contextualizar históricamente el descubrimiento, la conquista, las aportaciones demográficas y el modelo de explotación de América y su transcendencia en la España moderna... identificar las causas del proceso emancipador de la América española evaluando sus repercusiones" y, finalmente, recomienda "poner ejemplos de hechos significativos de la historia de España relacionándolos con su carácter internacional, en especial el europeo y el hispanoamericano... identificar y establecer conexiones de la historia de España y los que simultáneamente suceden en el contexto internacional, en especial en Europa y en Hispanoamérica, resaltando las repercusiones que se derivan en uno y otro ámbito". Como se habrá comprobado, es en los criterios de evaluación donde se hace patente la voluntad de impulsar lo que podríamos definir como una dimensión iberoamericana en la enseñanza de la historia en España, complementaria de la dimensión europea.

Los programas oficiales del Ministerio de Educación pueden ser legalmente ampliados y desarrollados por las distintas administraciones regionales-autonómicas. Nos vamos a servir del ejemplo de la Comunidad Valenciana para mostrar que, en ocasiones, como ocurre en el presente ejemplo, si pueden darse algunos cambios, aunque no sean básicos. En el caso valenciano ${ }^{7}$ podemos observar, en lo referente a la ESO, que se añaden algunos aspectos importantes como los siguientes: "el descubrimiento y la colonización de América y su impacto económico... la colonización americana: organización territorial, transformaciones económicas y sociales... arte y cultura en la América hispana... y la emancipación de la América Hispana", todos ellos presentes en el segundo curso de ESO, excepto el último que lo está en el cuarto curso. En lo concerniente a los dos cursos del bachillerato ${ }^{8}$, los cambios también son considerables en cuanto que incrementan la atención al mundo actual iberoamericano tanto

${ }^{7}$ Diario Oficial de la Generalidad Valenciana, 24-7-2007.

${ }^{8}$ Diario Oficial de la Generalidad Valenciana, 15-7-2008. 
desde la visión histórica como, sobre todo, desde la geográfica. En este último sentido cabe subrayar la forma en que se destaca explícitamente, y de forma muy novedosa, la que hemos denominado como dimensión iberoamericana como una de las finalidades de la enseñanza de la historia y de la geografía: "comprensión y explicación del espacio territorial español... del espacio europeo... sin olvidar otras regiones como el espacio iberoamericano y el ámbito mediterráneo con los que existen también estrechas relaciones de tipo cultural e histórico" (introducción a la geografía de bachillerato). Más adelante, en el bloque 2 de este mismo programa, se volverá a insistir en tales apreciaciones: "España en su desarrollo histórico ha condicionado otras concepciones socioespaciales entre las que destaca el espacio europeo, sin olvidar el iberoamericano y el mediterráneo, todos ellos en proceso de construcción... España desempeña un papel privilegiado en las relaciones con los países iberoamericanos".

Un problema distinto es el de la extensión o profundidad con que estas temáticas son abordadas en los manuales, como analizaremos en los apartados posteriores. Esta cuestión depende directamente de la mayor o menor cantidad de programa y de contenidos históricos asignados a cada curso. En el caso de la secundaria obligatoria, exactamente en el segundo curso de la ESO, los contenidos abarcan, desde una óptica internacional, al conjunto de las edades media y moderna, lo que, dada la amplitud del temario, es ciertamente un grave inconveniente para un posible tratamiento de los temas incluidos que vaya más allá de una visión rápida y superficial de los mismos. Otro tanto ocurre con los más recientes programas de la historia de España del último curso del bachillerato, ya que en esta materia debe de abordarse el conjunto de la historia española, desde la prehistoria hasta la actualidad, dentro de las características tradicionales de las historias generales. En los programas inmediatamente anteriores, los de 1992, esta materia estaba dedicada exclusivamente a la historia contemporánea de España, a los siglos XIX y XX, lo que posibilitaba un tratamiento más intenso de las cuestiones y procesos históricos abordados en las aulas.

Dadas las características del mercado editorial español en el que hay libertad de elección de los manuales escolares entre aquellos ofrecidos por las distintas editoriales, hemos centrado nuestro análisis en los libros de texto realizados por las cinco editoriales con mayor presencia en las aulas y que, en su conjunto, suponen aproximadamente el ochenta por ciento de los manuales utilizados en las aulas españolas de educación secundaria?.

${ }^{9}$ Estas cinco editoriales son Anaya, Santillana, S.M., Vicens Vives y Ecir. 


\section{Tratamiento temático de la historia iberoamericana}

En este apartado abordaremos los distintos temas anunciados previamente y para ello seguiremos un orden cronológico que nos permita explicitar con mayor facilidad las principales características del relato histórico seguido en los manuales.

\section{Las sociedades amerindias o precolombinas}

Ambas denominaciones son las más usuales a la hora de tratar los tiempos anteriores a la llegada de los españoles a las tierras americanas. Por lo general se suele diferenciar entre las "grandes, prósperas y florecientes civilizaciones e imperios existentes" (Vicens Vives, $4^{\circ}: 20-21$ ), en referencia a las culturas maya, azteca e inca, de las que se destaca especialmente sus "grandes logros en matemáticas, astronomía o escritura" (Santillana, 20: 118-119) o en "arquitectura y en sistemas de cultivos muy perfeccionados" (Anaya, $4^{\circ}$ : 34-36) y aquellas otras culturas amerindias no tan importantes o menos desarrolladas que, ocasionalmente, también son citadas pero apenas analizadas (así, por ejemplo, se cita las culturas olmeca, teotihuacana y mochica: Santillana, $2^{\circ}$ : 118-119) o se habla de la existencia de centenares de tribus dispersas "con una organización social y política menos compleja".

Por término medio estas culturas y sociedades precolombinas suelen ocupar un espacio de dos a cuatro páginas en las que se incluye habitualmente un mapa histórico con sus respectivas ubicaciones y las imágenes de algunos de sus artefactos artísticos más representativos. La presencia de estas poblaciones precolombinas ha ido aumentando a lo largo de los últimos treinta años y convirtiéndose en un apartado presente en todos los manuales, aunque sea de forma escueta. Otro aspecto que se destaca en los manuales más recientes es el de la consideración del grado de desarrollo alcanzado por algunas de estas culturas frente a un tratamiento más "salvajista o primitivista" que se daba en manuales de periodos anteriores. En algunos manuales de tipo alternativo esta cuestión se aborda de manera más detallada y precisa a partir de la puesta en cuestión de la definición de "salvajes" aplicada a las culturas amerindias por algunos de los europeos llegados a América a finales del siglo XV (proyecto Kairós, $2^{\circ}$ : 123-126). Otro aspecto interesante y novedoso en los actuales manuales es la conexión que se establece entre las culturas precolombinas y la existencia actual de poblaciones "indígenas" (esta es la denominación más frecuente). Eso ocurre en la obra que acabamos de citar, la del proyecto Kairós, pero se da también en otros manuales como, por solo citar un ejemplo más, el de Santillana $\left(2^{\circ}: 228\right)$, en este caso en relación con los indígenas de Guatemala y sus numerosos problemas actuales. Esta conexión entre pasado y presente puede ser muy sugerente desde 
un punto de vista tanto historiográfico como didáctico, como también lo es la introducción de la "polémica sobre los indios" entre distintos teólogos españoles y la propia administración monárquica del momento en relación con el trato y valoración humana que debía de tenerse respecto de las poblaciones indígenas (por ejemplo en Santillana, $2^{\circ}$ : 194-195).

\section{El "descubrimiento", la conquista y la colonización de América}

El "descubrimiento" de América suele estar contextualizado dentro de los viajes que los "europeos" (esta es la expresión reiteradamente utilizada, aunque se refieran casi exclusivamente a portugueses y castellanos) realizaron a lo largo del siglo XV en la búsqueda de nuevas rutas comerciales con el Oriente, especialmente a partir de la conquista de Constantinopla por los turcos y las dificultades que este cambio comportó para la continuidad del comercio europeo con el Oriente. Este cambio supuso la búsqueda de nuevas rutas sea bordeando África, sea adentrándose por el océano Atlántico. Fueron los nuevos conocimientos cartográficos y técnicos los que lo hicieron posible, según la mayoría de los manuales.

La denominación más frecuente de todo este proceso sigue siendo la de descubrimiento, pero sin entrecomillar como nosotros hemos hecho en el título de este apartado. En algunas ocasiones se utiliza la expresión de "puesta en contacto de pueblos que no se conocían" (Santillana: $\left.2^{\circ}: 120\right)$; la de "encuentro" (SM: $2^{\circ}$ Bachillerato: 86-87) o, de forma más dramática, la de "choque de culturas" (Kairós: 20: 131).

La consecuencia principal de estos "descubrimientos", desde la perspectiva europeísta, que es la que predomina en estos manuales, fue la del "comienzo de la hegemonía europea sobre el resto del mundo" (Santillana: $2^{\circ}$ : 120) y la pugna entre los principales países europeos del momento por ampliar sus dominios y sus zonas de influencia en otros continentes: "Esta rivalidad se prolongó durante cinco siglos".

Las consecuencias generales de este proceso colonizador también son relatadas en estos manuales desde otras perspectivas, sea la americanista, sea la castellana. Los aspectos más destacados son los que a continuación enumeramos.

Los cambios demográficos fueron importantes tanto en lo referente a un descenso considerable de la población amerindia, en los momentos iniciales de la conquista, por causa de las guerras y especialmente por las enfermedades "que llevaron los europeos, contra las que los indios no disponían de defensas naturales" (Santillana: $\left.2^{\circ}: 164\right)$ como por la generación de una sociedad basada en criterios raciales. Este nuevo tipo de sociedad estaba integrada por cuatro grupos 
sociales claramente diferenciados: los españoles, que ocupaban la posición superior y ejercían los cargos de gobierno, poseían las tierras y controlaban el comercio; los mestizos, que ocupaban una situación intermedia; los indios que realizaban la mayor parte de los trabajos manuales, agrícolas y mineros $y$, finalmente, los negros, que eran mayoritariamente esclavos, procedentes de África, que no contaban con ninguna ley que los protegiese y que prontamente sustituyeron a los indios en los trabajos más duros.

Las transformaciones económicas también fueron extraordinarias: "el oro y la plata americanos estimularon el comercio mundial, y el centro de gravedad de la economía europea se trasladó desde el Mediterráneo al Atlántico. Las nuevas plantas y productos procedentes de América (patata, tomate, maíz, tabaco, bebidas fermentadas, cacao, etc.) se introdujeron en la agricultura, en la alimentación y en los hábitos de consumo de los europeos" (Anaya: $4^{\circ}: 36$ ). Las colonias americanas, a su vez, se convirtieron en un mercado donde vender los productos manufacturados europeos.

También los cambios culturales fueron importantes especialmente en las zonas más pobladas del centro y sur de América, que fueron las preferidas por los colonizadores. Tanto la lengua castellana como la religión católica fueron las muestras más patentes de estos cambios que se dieron en todos los ámbitos sociales: "los españoles cambiaron las formas de vida de los indígenas, mediante un proceso de colonización a través del cual introdujeron la cultura, la religión, la lengua, el arte y las leyes de Castilla" (Vicens Vives: $4^{\circ}: 50$ )

Tal vez lo más interesante de estos nuevos manuales sea la introducción de los debates y polémicas que se originaron respecto de la forma en que debían de ser considerados y tratados los amerindios. A la ya anteriormente citada polémica entre los teólogos españoles (especialmente entre Bartolomé de las Casas y Juan Ginés de Sepúlveda) a propósito de la plena condición humana de los indios, habría que añadir la relacionada con las encomiendas y los abusos que en ellas se produjeron sobre los indios asignados a tales posesiones y su sustitución por las reducciones o poblados, en que sólo habitaban los indios, bajo la autoridad de la corona, que salvaguardaba sus derechos. Desde esta perspectiva también son sugerentes algunas de las actividades que se propone al alumnado como las relacionadas con el distinto punto de vista y las distintas valoraciones pertinentes entre europeos e indios a propósito de la colonización (Vicens Vives: $4^{\circ}$ : 56; Santillana: $2^{\circ}$ : 167) o las que cuestionan el estereotipo de "salvajes" aplicado a las culturas y sociedades indias (Kairós: $2^{\circ}$ : 124).

También es de destacar que en los actuales manuales de historia se ha pasado de una historia más factual y descriptiva, que era la más frecuente en los manuales anteriores a 1980, a una historia parcialmente más interpretativa 
y, a pesar del eurocentrismo predominante, ahora ya aparecen relatos más pluriperspectivistas, en los que las apreciaciones de los amerindios se hacen presentes y son relatos también más pluridimensionales y ya no solo centrados en un enfoque político de las cuestiones abordadas, sino que se hacen presentes otras muchas dimensiones sociales, culturales o económicas de la historia.

Los personajes más destacados en estas narraciones históricas son los "descubridores" por una parte y los conquistadores por la otra, a los que se suman, en menor cantidad, algunos amerindios y otros personajes no vinculados directamente con la colonización. En este sentido, los personajes más citados son Cristóbal Colón, Fernando de Magallanes, Hernán Cortés, Francisco Pizarro, Juan Sebastián Elcano, Francisco de Orellana, Pedro de Valdivia, Juan de Garay, Moctezuma, Atahualpa, la india Malinche y Bartolomé de las Casas.

\section{La independencia de los países iberoamericanos}

El tema de las independencias iberoamericanas está incluido, casi sin excepción, en el capítulo dedicado a la crisis del Antiguo Régimen en España, que suele incluir un apartado dedicado a la denominada Guerra de la Independencia contra la invasión napoleónica; otro dedicado al proceso constitucional desarrollado en las Cortes de Cádiz; un tercero relacionado con la restauración absolutista y el cuarto dedicado al tema de las independencias iberoamericanas. Ocasionalmente este esquema se ve continuado, en el mismo capítulo, por el tratamiento de la revolución liberal en España. En los manuales de Historia del Mundo Contemporáneo el esquema anterior, que es el predominante, puede verse modificado y el tema de las independencias iberoamericanas suele incluirse en el capítulo dedicado a las revoluciones liberales, tanto europeas como americanas, del primer tercio del siglo XIX ${ }^{10}$. Mucho más excepcional es el tratamiento singularizado que presentan algunos otros manuales de esta misma materia escolar en los que se dedica un capítulo específico a la América del siglo XIX, casi exclusivamente orientado al estudio de los avatares y la evolución de los países iberoamericanos antes y después del proceso independentista ${ }^{11}$. Este último enfoque es de gran importancia para el tema que nos ocupa, pues permite un tratamiento más conjuntado, o menos fraccionado, del proceso independentista y del desarrollo posterior de las repúblicas iberoamericanas.

Los manuales suelen distinguir entre precedentes o causas remotas y causas inmediatas. Ocasionalmente esta diferenciación se formula constatando

\footnotetext{
${ }^{10}$ Así, por ejemplo, en el manual de la editorial Ecir (Grupo Edetania: Historia del Mundo contemporáneo. Valencia, Ecir editorial, 2002.

${ }^{11}$ Este es el caso del manual de la editorial S.M. (Javier M. Donézar: Mundo Contemporáneo. Madrid, editorial S.M., 1990, capítulo 6: América en el siglo XIX, pp.118-139).
} 
que la independencia fue producto de "un largo proceso en el cual Hispanoamérica habia ido dándose cuenta de su propia identidad, tomando conciencia de su distinta cultura y, sobre todo, de la necesidad de velar por sus propios recursos" ${ }^{21}$. Este largo proceso previo se contrapone, en ocasiones, con el carácter rápido y violento de las revoluciones por la independencia. La concreción cronológica de este "largo proceso" y de sus principales particularidades no está, sin embargo, especialmente definida en los manuales. Para el autor de la anterior cita, este proceso se inició en el siglo XVIII, sin mayores precisiones. Para los autores de otro manual, sin embargo, las causas remotas parten ya desde los mismos inicios de la colonización, aunque se intensifiquen en la segunda mitad del siglo XVIII. Este segundo manual es también de los pocos libros de texto que da información sobre las insurrecciones "neoincaicas" del siglo XVIII.

Todos los manuales suelen aducir cuatro tipos de causas o factores que son desarrolladas de manera más o menos sintética en cada caso: causas económicas, causas sociales, causas político-sociales y causas ideológicas.

De entre las causas económicas se suele destacar la imposibilidad de comerciar directamente con los mercados internacionales, la resistencia al incremento de los tributos y el deseo insatisfecho de controlar los gastos. Para alguno de los manuales analizados este tipo de causas sería el más importante

A la hora de analizar las causas sociales subyacentes al proceso independentista, los manuales presentan mayores matices y diferencias que respecto de las causas económicas en las que se daba una considerable uniformidad. Estas diferencias residen fundamentalmente en el mayor o menor protagonismo asignado a la burguesía criolla y en la forma en que se describe las relaciones de este grupo con los restantes sectores sociales. Por una parte nos podemos encontrar con descripciones que establecen las diferentes situaciones sociales y el protagonismo de los criollos:

La población se hallaba dividida en grupos y subgrupos tipificados con muy diversos caracteres étnicos y sociales. Las clases altas estaban compuestas por una aristocracia de origen peninsular y la burguesía criolla-propietaria de haciendas y minas- refinada y culta, educada, con mucha frecuencia, en Europa; los grupos restantes los formaban los indios; los negros esclavos; los marginados mestizos y los mulatos. Como se puede deducir, el grupo más activo en el proceso de independencia acabaría siendo el criollo, por cuanto, por un lado, ansiaba participar en el poder político y, por otro, manejaba los resortes económicos y, con ellos, las relaciones comerciales con el exterior... la

\footnotetext{
${ }^{12}$ Javier M. Donézar: Mundo Contemporáneo. Madrid, S.M. 1990, p. 120.
} 
postergación de la burguesía criolla ante los peninsulares fue derivando en un conflicto en el que los criollos buscaban el poder que creían les correspondía por ser los impulsores de la economía y por dominar a las clases inferiores: indios, mestizos, mulatos y negros ${ }^{13}$.

En otros manuales, el protagonismo criollo queda igualmente destacado, pero se intensifica las diferencias y desigualdades existentes dentro de la sociedad iberoamericana:

A la hora de la independencia fue muy distinto el comportamiento de las comunidades americanas según fuese la estructura social y étnica de cada territorio. Así, mientras los criollos venezolanos se apoyaron en las comunidades negra y mestiza, en México, el protagonismo indígena fue muy claro. En cambio, en otros lugares, como el Alto Perú, era tal la distancia social y la desconfianza entre criollos e indígenas que apenas existía espíritu independentista entre las élites dominantes que preferían seguir vinculadas con la metrópoli... Bajo la bandera del patriotismo se trata de ocultar el modelo criollo de nación, en el que la mayoría de los ciudadanos quedan marginados...el proceso de insurrección americana tendría, pues, un marcado carácter clasista ${ }^{14}$.

Como veremos posteriormente, esta constatación es la que está en la base de la frecuente definición presente en los manuales de los conflictos independentistas como guerra civil.

La mayor parte de los manuales analizados incluyen también una serie de factores político-administrativos como causantes del proceso independentista. Con ello se refieren fundamentalmente a la designación preferente de los españoles peninsulares para los altos cargos políticos oficiales, así como para el gobierno del comercio transatlántico. Esta decisión de la administración española hacía que los criollos, en gran parte dedicados al ejercicio de las profesiones liberales, especialmente la de abogados, se considerasen relegados a cargos menores tanto en el conjunto de la administración pública como en las instituciones eclesiásticas. Esta variante causal es puesta en relación frecuentemente con las de tipo económico vistas previamente.

Respecto de las causas ideológicas, la coincidencia de los manuales es muy grande y las únicas diferencias existentes entre los distintos libros de texto reside en la mayor o menor profundidad con que se las aborda:

Los criollos se habían formado en una conciencia de emancipación como resultado de sus contactos con las ideas reformistas ilustradas y liberales. Habían leído a los filósofos y pensadores políticos franceses; estaban al

\footnotetext{
${ }^{13}$ Javier M. Donézar: o. c., p. 120-121.

${ }^{14}$ Fernando García de Cortázar et al.: Historia. Bachillerato Logse. Madrid, Anaya, 1998.pp. 147-148.
} 
día de las noticias sobre la independencia de los Estados Unidos y sobre la Revolución Francesa. Quisieron, por tanto, depender en todo caso de una España liberal pero no absolutista. Sólo faltaba añadir motivos inmediatos o externos, como la invasión napoleónica de España en 1808, para que diera comienzo el movimiento revolucionario ${ }^{15}$.

Formulaciones semejantes se dan en la práctica totalidad de los manuales analizados, extendiendo sus efectos también a la independencia de Brasil, lo que supone una innovación muy reciente dentro de los manuales españoles, ya que los precedentes no solían realizar este tratamiento conjunto de las independencias iberoamericanas.

Todos los manuales distinguen claramente dos etapas en este proceso independentista. Una primera fase (1810-1815), paralela a la Guerra de la Independencia en España y a la posterior restauración del absolutismo, que comportó la neutralización de los movimientos independentistas iniciales, y una segunda fase (1816-1825) en la que se consumó el proceso de independencia de los países iberoamericanos. En algunos manuales se destaca también la existencia de un "preámbulo" a estas dos fases encarnado en el intento fracasado del "precursor" Francisco Miranda, en 1806, de invadir el territorio de la actual Venezuela.

La primera fase del proceso independentista suele tratarse de forma muy paralela a lo que estaba aconteciendo en España en los inicios de la guerra contra la invasión napoleónica. Dentro de esta primera fase del proceso suele destacarse cuatro importantes focos del movimiento independentista: México (del que se destaca el carácter campesino y popular de su levantamiento), Caracas y Perú (considerado como el principal núcleo de la resistencia española al proceso independentista) y Buenos Aires, definido como el centro independentista más consistente en esta primera fase.

Todos los manuales acotan el final de este primer periodo con la restauración de la monarquía absoluta de Fernando VII en España y el restablecimiento del predominio español en casi todos los territorios iberoamericanos al conseguirse el sometimiento de las diversas Juntas existentes, con la excepción de las del Río de la Plata.

La mayoría de los manuales suelen utilizar el concepto de guerra civil para denominar una de las componentes del proceso independentista incluso en esta primera fase. También suelen mostrarse críticos con la reacción llevada a cabo por Fernando VII tras su reposición en el trono español:

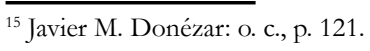


Nada pueden hacer los gobiernos de Madrid contra los brotes independentista, ni tampoco las Cortes de Cádiz ofrecen solución alguna. La lucha por la independencia pronto degenera en guerra civil entre los partidarios de la secesión y los fieles a la metrópoli, o entre la burguesía nacionalista y los explotados mestizos e indios, manipulados por uno u otro bando... Deseos de emancipación, enfrentamientos sociales y rivalidad entre el liberalismo y la reacción constituyen, en definitiva, el núcleo de la contienda americana... Concluida la guerra hispano-francesa, el gobierno de Fernando VII responde a los secesionistas con el envío de un modesto ejército que logra pacificar algunos territorios, pero que no consigue evitar la independencia formal de Argentina en 1816. La intransigencia de la metrópoli ante cualquier fórmula de autonomía impide el arreglo al soliviantar a los dirigentes americanos y lanzarlos definitivamente al enfrentamiento ${ }^{16}$.

La segunda etapa del proceso independentista viene caracterizada en los manuales por diversas consideraciones complementarias entre sí. Por una parte, se la suele definir como una guerra colonial ${ }^{17}$, dado que en ella se intentó someter militarmente a los patriotas americanos. Por la otra, se destaca su generalización ${ }^{18}$ al conjunto de Iberoamérica y el carácter más organizado y coordinado de los movimientos independentistas y de las acciones militares ${ }^{19}$. Finalmente se subraya el gran acierto estratégico de los principales dirigentes de la sublevación y las dificultades de la corona española para poder organizar una defensa adecuada de sus intereses. En algunos de los manuales más recientes, como ya indicamos anteriormente, la particularidad del proceso independentista de Brasil es también abordado en este apartado. Los mapas históricos, presentes en todos los manuales, resaltan también este carácter global del proceso de las independencias de los países iberoamericanos.

Los manuales suelen narrar con cierto detalle el desarrollo de esta segunda fase de las independencias iberoamericanas. Se suele distinguir los tres principales frentes de la contienda, el del sur, el del norte y el mexicano-centroamericano y se enumera los principales hitos históricos del proceso citando los nombres de los grandes dirigentes y de las principales batallas, como reseñaremos posteriormente. En algunos manuales el carácter conjunto del proceso independentista, desde sus inicios hasta su consumación, viene subrayado con expresiones tan explícitas como las de un proceso imparable ${ }^{20}$. La enumeración de los países iberoamericanos constituidos a partir del proceso independentista, así como las fechas de su

\footnotetext{
${ }^{16}$ Fernando García de Cortázar et al.: o.c., pp. 149.

${ }^{17}$ Grupo Edetania: o.c., p.84.

${ }^{18}$ M. García Sebastián et al.: o.c., p. 139.

${ }^{19}$ José A. García de Cortázar et al.: Historia. $2^{\circ}$ ciclo ESO. Madrid, Santillana, 1996, p. 233.

${ }^{20}$ Juan Santacana y G. Zaragoza: Historia 2. Bachillerato. Madrid, S.M., 1999, p.124.
} 
declaración de independencia, vienen reseñados en todos los manuales, tanto en el texto de los autores como, de manera más exhaustiva, en los mapas históricos que los acompañan.

La valoración global del desarrollo del proceso independentista suele ser bastante matizada en los manuales españoles y con consideraciones ponderadas que incluyen interesantes elementos críticos respecto de la comprensión de tal proceso:

El amplio movimiento emancipador americano no fue comprendido en España. Los dirigentes españoles, tanto los liberales como los absolutistas, imaginaban que podrían controlar el proceso. Para los diputados liberales de Cádiz, América formaba parte de España y consideraban que la Constitución ya había reconocido a los americanos como parte integrante de la nación; por tanto, no había más que discutir. Para los absolutistas y el propio monarca, la insurrección americana era una cuestión de bandidaje, que se debía solucionar mandando tropas y sometiendo a los rebeldes. Así pues, las propuestas de compromiso que realizaron algunos diputados americanos no prosperaron y fue imposible alcanzar ningún acuerdo. Por otra parte, España no contaba con los medios necesarios para derrotar a los independentistas, y aunque buscó el apoyo de la Santa Alianza, ésta no podía hacer nada fuera de Europa. En cambio, los americanos contaron siempre con el respaldo de Estados Unidos y de Gran Bretaña, muy interesados en poder comerciar libremente con los mercados americanos ${ }^{21}$.

Las consecuencias de las independencias y la situación y problemas existentes en las nuevas repúblicas iberoamericanas y en España forman también parte del estudio presente en los manuales y existe una coincidencia bastante generalizada en la descripción de las consecuencias. Se destaca, por una parte, el éxito del proceso independentista, tanto en su dimensión militar como política e institucional. Se subraya, por la otra, las escasas transformaciones sociales y económicas que se dieron en las nuevas repúblicas y que comportaron una fuerte división social y el continuado temor de los criollos a las posibles revueltas de las masas campesinas más desfavorecidas. Esta situación de inestabilidad social, junto con el protagonismo de los militares en las guerras independentistas, son las principales razones aducidas para explicar el desarrollo de un marcado caudillismo militar entre los grupos dirigentes de las recién emancipadas repúblicas. A este conjunto de factores se suele atribuir también su posterior dependencia económica tanto de Gran Bretaña, inicialmente, como de Estados Unidos, ya posteriormente.

En algunos manuales el grado de dependencia económica exterior de las nuevas repúblicas se plantea de forma interrogativa y más compleja o matizada:

\footnotetext{
${ }^{21}$ Juan Santacana y G. Zaragoza: o.c., p.125.
} 
¿Hasta qué punto los americanos habían conseguido la independencia económica? Cierto era que habían conseguido la independencia política, estaban elaborando constituciones y estableciendo sus nuevas formas de gobierno. Pero el nacionalismo económico, la hostilidad a la presencia extranjera o el resentimiento ante los controles extranjeros estaban ausentes de las actitudes del momento, porque mientras las nuevas naciones rechazaban el monopolio español, daban la bienvenida a los extranjeros que eran partidarios de la libre competencia y que aportaban el ansiado capital, los productos manufacturados y los primeros inventos de la revolución industrial al tiempo que invertían grandes sumas en explotaciones agrarias de algodón o productos tropicales, consolidando la agricultura de monocultivo y manteniendo en América Latina una economía basada en la renta de materias primas... El problema para las nuevas naciones era qué aceptar: si la propuesta de protección de los Estados Unidos (la doctrina de Monroe) o la llegada real de productos ingleses. Era fácil aprobar una América para los americanos, pero ¿cómo? Los nuevos nacionalismos carecían de unidad y estaban desprovistos de contenido social. Las masas populares tenían escasa devoción por las naciones en que vivían; de ahí que fuera difícil aceptar unas líneas de independencia americana como las que proponía Monroe, máxime cuando los mismos Estados Unidos no estaban proporcionando soluciones prácticas $^{22}$.

La fragmentación política en múltiples repúblicas frente al proyecto bolivarista de un sistema de naciones amigas, así como la escasa integración social conseguida en las mismas, es frecuentemente considerada un fracaso por la mayor parte de los manuales analizados:

Los nuevos países siguieron trayectorias muy distintas. También se frustraron las esperanzas de algunos sectores de crear sociedades libres, dotadas de sistemas políticos liberales avanzados. Los criollos concentraron el poder económico y el poder político, no se cumplieron las promesas hechas a los indígenas que habían luchado por la independencia, ni se concedió, por lo general, la libertad a los esclavos negros. Por ello, Bolívar escribía, en 1830, al Congreso colombiano: la independencia es el único bien que hemos adquirido, a costa de los demás ${ }^{23}$.

La valoración expuesta en los párrafos precedentes es la predominante en los manuales españoles, pero no es la única, dado que en algún libro de texto se desarrolla un razonamiento distinto, incluso contrapuesto a los anteriores, pero tal vez más real:

\footnotetext{
${ }^{22}$ Javier M. Donézar: o. c., p. 126-127.

${ }^{23}$ Joaquín Prats et al.: Historia del Mundo Contemporáneo. Bachillerato. Madrid, Anaya, 2002, p.77.
} 
Algunos autores consideran esta guerra como una revolución frustrada, porque la desigualdad social y el dominio colonial no cambiaron con los nuevos gobernantes, que sustituyeron a los antiguos administradores españoles. Pero es evidente, que quienes dirigieron la lucha contra España perseguían tres objetivos muy claros: la independencia política, el régimen republicano y la libertad de comerciar; y esos tres objetivos fueron alcanzados. Por lo tanto, en ese sentido, no hubo revolución frustrada ${ }^{24}$.

Los manuales no suelen dedicar un gran espacio al análisis de las consecuencias que la independencia de los países iberoamericanos supuso para España, pero son muy contundentes en resaltar sus efectos económicos (tanto hacendísticos como comerciales) y políticos y la gran trascendencia de los mismos:

Sin sus territorios americanos, España queda relegada definitivamente a un papel de potencia de segundo orden y pierde un inmenso mercado y unos recursos, muy necesarios en un momento en que otros países europeos comienzan su industrialización ${ }^{25}$.

Los nombres de los principales personajes del proceso independentista están presentes en la práctica totalidad de los manuales analizados, especialmente a la hora de describir las etapas de tal proceso y las áreas geográficas en que se desarrolló. Menos frecuente es que se exponga una pequeña biografía de los grandes líderes revolucionarios, con la excepción de Bolívar y, en algunos casos, de San Martín. Ambos personajes aparecen nombrados en todos los manuales yes bastante usual que se reproduzca algún retrato suyo y algunos de sus textos históricos. También suele citarse reiteradamente los nombres de Francisco Miranda, los de los curas Hidalgo y Morelos o el del general Sucre. Algo menos frecuentes son los nombres de Guerrero o de los generales Itúrbide y O’Higgins.

Las grandes batallas constituyen el segundo tipo de hitos destacados en los manuales. Sus nombres y las fechas en que tuvieron lugar se hacen presentes tanto en el texto escrito como en los mapas históricos. De entre las más reiteradamente citadas en el texto de los autores de los manuales cabe destacar las de Boyacá, Maipú, Carabobo, Pichincha y Ayacucho.

La independencia o emancipación de las últimas colonias iberoamericanas, las de Cuba y Puerto Rico, sólo son abordadas con cierta extensión en los manuales de Bachillerato y no en los de la ESO (por ejemplo en la editorial Santillana: $2^{\circ}$ bachillerato, páginas 198-199 y 220-222).

En términos generales, las imágenes icónicas de los actuales manuales de historia presentan una serie de características que conviene conocer antes de

\footnotetext{
${ }^{24}$ Grupo Edetania: o.c., p. 203.

${ }^{25}$ Fernando García de Cortázar et al.: o.c., pp. 149.
} 
entrar en el análisis de las peculiaridades de las imágenes relacionadas con las independencias iberoamericanas.

Una primera constatación, aplicable a la mayor parte de los manuales, es el aumento considerable del número de imágenes contenidos en ellos y del espacio que se les asigna. Hasta hace pocos años se solía dar por aceptable un porcentaje medio próximo al cincuenta por ciento para las imágenes, pero en los más recientes manuales este promedio es habitualmente más alto y, especialmente en el caso de las editoriales más poderosas, habría que incrementarlo en algunos puntos más. Una segunda constatación es la del aumento progresivo del color en las mismas. La tercera constatación es la del aumento de la iconicidad de las imágenes. Por iconicidad entendemos el grado de semejanza existente entre la imagen y el objeto o acción que se representa. El principal responsable de este incremento es el muy frecuente uso de las reproducciones fotográficas de muy diferentes tipos, que han eliminado prácticamente la presencia de los dibujos o esquemas simplificados en los manuales de secundaria.

Las temáticas reflejadas en estas imágenes han ampliado de manera muy notable su diversidad. Obviamente este cambio tiene mucho que ver tanto con las nuevas orientaciones historiográficas, las nuevas formas de hacer historia, como con las nuevas perspectivas y orientaciones que los actuales diseños curriculares han posibilitado. Los cambios temáticos más significativos están relacionados, en términos generales, con la disminución de los aspectos "nacional-heroizadores" de la enseñanza propuesta de la historia. Los anteriormente omnipresentes héroes y grandes personajes, así como sus hazañas, prioritariamente bélicas, han reducido enormemente su presencia, con la excepción de los representantes de la monarquía, que la han seguido mantenido. Sus espacios han sido sustituidos por imágenes relacionadas fundamentalmente con la vida cotidiana y con la cultura material de las distintas épocas tratadas (lo que ha permitido una mayor presencia de las mujeres, anteriormente casi absolutamente ausentes tanto en la parte escrita como en la icónica de los manuales escolares). En esta misma línea de transformación se ubica la reciente tendencia al uso de imágenes que tuvieron mayor difusión en el momento de su creación, sin que su presencia haya supuesto una disminución de las consideradas tradicionalmente como obras maestras únicas. En este sentido cabe destacar la progresiva presencia de los grabados, de las caricaturas, de los carteles de propaganda política o de las fotos de objetos e instrumentos procedentes de distintos tipos de museos.

\section{Los países iberoamericanos en los tiempos recientes}

Los tiempos posteriores a las independencias iberoamericanas han tenido una presencia bastante escasa en los manuales de historia hasta los últimos 
decenios. Su presencia se circunscribía casi exclusivamente a los tiempos actuales y lo hacía principalmente desde un punto de vista geográfico a la hora de abordar las grandes regiones del mundo. En los manuales actuales de historia esta presencia ha aumentado en casi todos ellos tanto en lo referido al siglo XIX como al siglo $\mathrm{XX}$ y a la actualidad inmediata. De todas maneras es aún bastante excepcional que la historia contemporánea iberoamericana se trate de manera detallada. En este sentido es una excepción positiva el manual de la editorial Anaya dedicado a la historia de mundo contemporáneo ya que al dedicar un apartado titulado "la historia en otros continentes" (distintos al europeo) al finalizar cada bloque temático centra su atención también en los países y sociedades iberoamericanas y, así, podemos encontrarnos con pasajes dedicados a los periodos entre "1789 y 1870: las nuevas naciones de América” (página 128); “1870-1914: América Latina: dictaduras y guerras” (página 212); “1914-1945: América Latina: industrialización y dependencia económica” (páginas 295-296);“América Latina: dependencia económica y desigualdad social" (páginas 351-353); "los problemas recientes de América Latina" (páginas 404-405) y "América Latina a comienzos del siglo XXI" (página 406). Estos pasajes, aunque sean breves, trazan las características fundamentales y las evoluciones y transformaciones experimentadas por el conjunto de los países iberoamericanos a lo largo de los dos últimos siglosy suponen una innovación muy interesante y sugestiva.

Algunos manuales ofrecen breves reseñas sobre la situación actual destacando tanto los avances democráticos como los persistentes problemas económicos:

Iberoamérica es un espacio muy variado y desigual. En los años ochenta y noventa del pasado siglo, con el final de la guerra fría, se repuso la democracia en Argentina, Chile y Nicaragua. La Cuba de Fidel Castro se mantiene como el único régimen de carácter comunista. El principal problema que tienen los países latinoamericanos es su dependencia económica de los Estados Unidos y el crecimiento desmesurado de su deuda externa [...] (Anaya: $4^{\circ}: 266$ ).

Los restantes manuales se expresan en términos muy semejantes.

Otro tema especialmente destacado es el de los avances en la coordinación política y económica entre los países iberoamericanos:

El desarrollo de los procesos de integración supranacional y de cooperación económica llegaría también al sur del continente americano. Tras la cumbre de Brasilia (agosto 2000) se planteó la creación de un espacio político y económico común para integrar las organizaciones de Mercosur (Mercado Común de América del Sur) y del Pacto Andino (Comunidad Andina desde 1996) (Anaya: $1^{\circ}$ bachillerato: 406 ). 
En esta misma línea interpretativa algunos manuales ofrecen una visión altamente positiva y esperanzada, aunque con problemas, de la actual realidad iberoamericana:

Aunque culturalmente existe una clara vinculación con España y Portugal, la actualidad iberoamericana se encuentra influida económicamente por Estados Unidos, al que le unen diversos tratados. A pesar de las dificultades económicas existentes y de que el enorme crecimiento demográfico hace difícil superar el subdesarrollo, la región presenta unas perspectivas de evolución muy favorables. (SM: $\left.3^{\circ}: 238\right)$.

Todos los manuales suelen abordar la cuestión de las migraciones actuales desde los países más o menos subdesarrollados hacia los más desarrollados y estas migraciones suelen reflejarse en mapas en los que obviamente aparecen los intercambios entre Iberoamérica y España, así como los existentes entre los países iberoamericanos y la Unión Europea o los Estados Unidos de Norteamérica, pero los intercambios entre los países iberoamericanos (incluyendo España y Portugal) no son objeto de un tratamiento particularizado y más amplio (incluso históricamente para mostrar los flujos de ida y vuelta que se han dado durante varios siglos) lo que iría en beneficio del incremento de los lazos existentes entre todos ellos y, de esta forma, en la intensificación de lo que podríamos definir como una dimensión específicamente iberoamericana. En este sentido, y ya para concluir este apartado, los programas oficiales dan cabida, como vimos en el capítulo segundo de esta investigación, a una profundización mucho más intensa de la dimensión iberoamericana que la plasmada en los manuales. Posiblemente el peso del código curricular aún es demasiado poderoso a la hora de redactar los manuales de historia y de geografía y, a pesar del incremento de la presencia de información sobre los países iberoamericanos, ésta aún no logra, en nuestra apreciación, ser lo suficientemente sólida y argumentada como para poder definir que se ha alcanzado en los actuales manuales: aún nos queda bastante trecho por recorrer, a pesar de los claros avances ya conseguidos, para poder confirmar que existe una amplia dimensión iberoamericana en los manuales escolares españoles de historia.

\section{A modo de valoración global}

La manera en que los manuales españoles tratan los temas relacionados con los actuales países iberoamericanos en su relación con España está exenta de descalificaciones y de estereotipos de cualquier tipo que pudieran ser rechazables historiográficamente o que pudieran molestar o indignar fundadamente a cualquier lector de alguna de las nacionalidades implicadas. La visión predominante está basada en la tolerancia, la comprensión y la concordia. 
El proceso independentista está presentado como un proceso de emancipación, fruto de un "largo proceso en el cual Hispanoamérica babia ido dándose cuenta de su propia identidad, tomado conciencia de su distinta cultura y, sobre todo, de la necesidad de velar por sus propios recursos", como se dice en uno de los manuales analizados y como también se refleja en uno de los documentos históricos reproducidos, redactado por Camilo Torres, uno de los dirigentes del movimiento independentista, incluido en estos manuales: "¿no estamos nosotros en la situación de bijos que alcanzan la mayoría de edad a la muerte del padre de familia? Cada uno de ellos pasa a disfrutar de sus derechos individuales, crea un nuevo hogar, y se gobierna a si mismo"26. En términos generales se puede afirmar que la interpretación histórica ofrecida está suficientemente equilibrada y ponderada, pues hace presentes las distintas voces e intereses que se hicieron presentes en el proceso colonizador y en el independentista, al menos en lo que concierne a los independentistas criollos y a los peninsulares. Tal vez este equilibrio no se dé de manera tan palpable en lo que respecta a las voces populares o subalternas de los indígenas, mestizos, negros y, obviamente, de las mujeres, pues aunque actualmente ya tengan cabida en los manuales sus reivindicaciones iniciales y su frustración tras las declaraciones de independencia, sus voces quedan minorizadas dentro del conjunto del relato histórico ofrecido.

Otro aspecto que los recientes manuales han mejorado es la presentación conjunta, en su más amplia dimensión iberoamericana, del proceso postindependentista y de los tiempos recientes. Esta actual innovación es positiva, pues permite tener tanto una visión menos parcelada del proceso en su globalidad como hacer más presente el desarrollo histórico de Portugal y de Brasil, que no estaba ni todavía está suficientemente destacado en los manuales españoles.

La fragmentación excesiva que los manuales practican a la hora de abordar los procesos históricos presenta muchos problemas para que los alumnos alcancen una comprensión más profunda de los temas abordados (la única excepción que hemos encontrado a este tratamiento fragmentado es la ofrecida en los materiales del ya citado Proyecto Kairós: $2^{\circ}$ : 122-155). Esta dificultad se hace presente en el conjunto de las cuestiones de las que nos hemos ocupado, especialmente en lo tocante al posterior reconocimiento legal de las independencias y al restablecimiento de las relaciones entre España y las nuevas repúblicas iberoamericanas, aspecto que apenas es incluido en los manuales en este proceso y que convendría introducirlo para suministrar una visión más completa del conjunto del proceso.

El establecimiento de relaciones entre el pasado y el presente está bastante ausente en los manuales, a pesar de la convicción, tanto de los didactas de la historia como del profesorado de esta materia, de que esta disciplina tiene como

${ }^{26}$ Javier M. Donézar: o.c., p.123. 
una de sus funciones fundamentales la de posibilitar el entendimiento del pasado y la comprensión más razonada y profunda del presente. Los manuales deberían impulsar esta dimensión más práctica del estudio de la historia, sea a través del texto de sus autores, sea mediante las preguntas y cuestiones dirigidas al alumnado con la información pertinente para que se realizasen estas muy convenientes interconexiones entre pasado y presente. Este enfoque ayudaría muchísimo a profundizar en esta posible dimensión iberoamericana de la enseñanza de la historia, que es la que actualmente nos ocupa y preocupa.

Como ya esbozamos anteriormente, al abordar el enfoque didáctico, el tratamiento de las imágenes es uno de los aspectos más claramente mejorables en los manuales. Tal como indicábamos, la conversión de las imágenes en auténticos documentos históricos no resultaría especialmente complicada y la inclusión de preguntas sobre las mismas tampoco. Como han demostrado diversos estudios recientes, las preguntas y cuestiones dirigidas a los alumnos sobre las imágenes son la forma más adecuada para conseguir de ellos una mirada atenta y analítica.

El uso indistinto de términos como Hispanoamérica, Iberoamérica y América Latina o Latinoamérica debería ser precisado en los momentos iniciales de su utilización. Podemos pensar que los alumnos los entienden con los matices particulares que cada una de estas denominaciones comporta, pero no suele ocurrir de esta manera y pueden convertirse, por tanto, en motivo innecesario de confusión.

Suele ocurrir que cuando se analiza la forma en que un determinado tema o proceso histórico es tratado en los manuales escolares se concluya afirmando que su presencia debería ser ampliada y profundizada. Nuestra conclusión es similar a la indicada, especialmente desde una doble consideración. Por una parte, tomando el ejemplo de lo que en Europa se está haciendo con el desarrollo escolar de la denominada dimensión europea, que tan positivos resultados está ofreciendo, que podría servir de modelo para el impulso de la deseada dimensión iberoamericana de la enseñanza de la historia. Por la otra, el aumento de la presencia de personas procedentes de los países iberoamericanos en una y otra parte del Atlántico debe ser tenida en cuenta y facilitar la comprensión mutua de las historias respectivas, pues esa es una de las formas de lograr una mayor integración y proximidad cultural entre el conjunto de los pueblos y de las personas que, entre otras posibles identidades razonables, nos podemos definir como iberoamericanas. A pesar de las enormes dificultades que cualquier modificación de los programas escolares supone, especialmente si estos están definidos desde una óptica enciclopedista y poco selectiva de los contenidos, en el caso de los manuales españoles tal vez fuese pertinente la simplificación del tema de las independencias iberoamericanas en la materia de Historia del Mundo 
Contemporáneo, que no es obligatoria para todo el alumnado, y la intensificación de su presencia, como contrapartida de la anterior simplificación, tanto en el curso final de la educación secundaria obligatoria como en el último curso del bachillerato, el año conclusivo de la educación secundaria. De esta forma también se atendería a una de las recomendaciones reiteradas por los didactas de la historia, la de tratar con mayor profundidad y menor fragmentación los temas seleccionados, evitando en lo posible su presentación esquemática y simplista, que resulta incomprensible y muy poco eficaz para el desarrollo de una auténtica conciencia histórica por parte del alumnado.

\section{Referencias}

AGUADO BLEYE, P. Manual de historia de América. Bilbao, 1929.

ALTAMIRA, R. Manual de Historia de España. Madrid: Aguilar, 1934.

ARÓSTEGUI, J. et al. Atalaya. Historia del Mundo Contemporáneo. Barcelona: Vicens Vives, 2003, p. 335.

ARÓSTEGUI, J. et al. Crisol. Historia. Barcelona: Vicens Vives, 2003, p. 377.

BALLESTER, R. Geografía e historia de América. Barcelona, 1928.

BURGOS, M. et al. Historia. 2. ESO. Madrid: Anaya, 2003, p. 294.

BURGOS, M. et al. Historia. 4. ESO. Madrid: Anaya, 2003, p. 294.

CASTRO, F de. Resumen de la Historia General de España. Madrid: imprenta de F. Martínez, 1850.

CERECEDA, F. Historia del Imperio Español y de la Hispanidad. Madrid: Razón y Fe, 1940 .

DONÉZAR, J. M. Mundo Contemporáneo. Madrid: S. M., 1990.

FERNÁNDEZ ROS, J. M. et al. Historia de España. 2. Bachillerato. Madrid: Santillana, 2009 , p. 448.

FERNÁNDEZ ROS, J. M. et al. Historia del Mundo Contemporáneo. $1^{\circ}$ Bachillerato. Madrid: Santillana, 2008, p. 423.

GARCÍA DE CORTÁZAR, F. et al. Historia: Bachillerato Logse. Madrid: Anaya, 1998.

GARCÍA DE CORTÁZAR, J. A. et al. Historia. 2. ciclo ESO. Madrid: Santillana, 1996.

GARCÍA FUERTES, M. A. et al. Historia. 4º Secundaria. Madrid: S. M., 2003, p.303.

GARCÍA SEBASTIÁN, M. et al. Limes. Ciencias Sociales, Historia 4. Educación Secundaria. Barcelona: Vicens Vives, 2003, p. 323.

GRUPO EDETANIA. Historia del Mundo contemporáneo. Valencia: Ecir, 2002, p. 503. GRUPO EDETANIA. Historia. $4^{\circ}$ Eso. Valencia: Ecir, 2003, p. 381.

GRUPO EDETANIA. Historia. Bachillerato. Valencia: Ecir, 2003, p. 455.

JAÉN MORENTE, A. Nociones de historia de América. Madrid, 1929. 
JUAN REDAL, E.; GREGORI SOLDEVILA, I. (Dirs.). Geografía e historia. 2. ESO. Comunidad Valenciana. Madrid: Voramar-Santillana, 2007, p. 279.

JUAN REDAL, E.; GREGORI SOLDEVILA, I. (dirs.). Geografía. 3. ESO. Comunidad Valenciana. Madrid: Voramar-Santillana, 2007, p. 303.

JUAN REDAL, E.; GREGORI SOLDEVILA, I. (dirs.). Historia. $4^{\circ}$ ESO. Comunidad Valenciana. Madrid: Voramar-Santillana, 2008, p. 351.

MADALENA, J. I.; P. MAESTRO.; E. PEDRO. Ciencias Sociales. Primer ciclo 2. Madrid: McGraw-Hill, 1996, p. 225.

MORENO ESPINOSA, A. Compendio de Historia de España. Cádiz: imprenta Revista Médica, 1873.

PRATS, J. et al. Historia del Mundo Contemporáneo. Bachillerato. Madrid: Anaya, 2002, p. $432-471$.

PRATS, J. et al. Historia. Bachillerato. Madrid: Anaya, 2003, p. 419-462.

SÁNCHEZ CASADO, F. Prontuario de Historia de España y de la Civilización Española. Madrid: librería de G. Hernando, 1867.

SANTACANA, J.; ZARAGOZA, G. Historia 2. Bachillerato. Madrid, S.M., 1999.

SANTACANA, J.; ZARAGOZA, G. Historia 2. Bachillerato. Madrid: S. M., 2003, p. 447.

TUSELL, J. et al. Historia del Mundo Contemporáneo. Madrid, S.M., 2002, p. 383.

VALDEÓN, J. et al. Geografía e historia de España y de los Países Hispánicos. Madrid, 1981.

Recebido em 20/03/2013

Aceito em 29/05/2013 